\title{
Association of nighttime hypertension with central arterial stiffness and urinary albumin excretion in dipper hypertensive subjects
}

\begin{abstract}
Dimitrios Syrseloudis, Costas Tsioufis, Ioannis Andrikou, Anastasia Mazaraki, Costas Thomopoulos, Costas Mihas, Theodoros Papaioannou, Iraklis Tatsis, Eleftherios Tsiamis and Christodoulos Stefanadis

Both blood pressure (BP) non-dipping and nighttime hypertension have been associated with accelerated target-organ damage (TOD). However, increased nighttime BP in subjects with a dipping circadian BP profile has never been reported or associated with TOD. Here, we investigated the relationships of nighttime BP with indices of vascular and kidney damage in dipper hypertensive subjects. We studied 402 subjects with untreated stage I-II essential hypertension. According to ambulatory BP recordings, 127 dipper subjects were selected and subdivided into nighttime hypertensives (NH, $n=69$ ) (nighttime BP $\geqslant 120 / 70$ ) and nighttime normotensives (NN, $n=50$ ) (nighttime BP $<120 / 70 \mathrm{~mm} \mathrm{Hg}$ ). All participants underwent echocardiographic examination and assessments of carotid-to-femoral pulse wave velocity (c-f PWV), albumin-to-creatinine ratio (ACR), metabolic profile and high sensitivity C-reactive protein (hs-CRP) level. Compared with NN dippers, NH dippers had higher $c$-f PWV $(P<0.001)$, ACR values $(P=0.01)$ and hs-CRP levels $(P<0.001)$. Multiple regression analysis showed that nighttime BP was more correlated with $c-f$ PWV and ACR than was daytime BP. Among dippers, nighttime BP is associated more closely with c-f PWV and ACR than is daytime BP. These findings imply that even in dippers, absolute nighttime BP values should be taken into account when predicting surrogate end points such as arterial stiffness and urinary albumin excretion.

Hypertension Research (2011) 34, 120-125; doi:10.1038/hr.2010.192; published online 21 October 2010
\end{abstract}

Keywords: arterial stiffness; inflammation; microalbuminuria; nighttime hypertension

\section{INTRODUCTION}

Arterial stiffening, an integral part of the aging process and a consequence of several disease states, ${ }^{1}$ has been linked to an increased risk of cardiovascular morbidity and mortality in subjects with hypertension, chronic kidney disease or diabetes, as well as in the general population. ${ }^{2}$ In addition, arterial stiffness has been correlated with microalbuminuria in the context of microvascular renal disease, generalized endothelial dysfunction and vascular inflammation. ${ }^{3}$ On the other hand, enhanced urinary albumin excretion has been recognized as a predictor of cardiovascular events and mortality ${ }^{4,5}$ in hypertensive patients.

Although the relationships of arterial stiffness, microalbuminuria and low-grade systemic inflammation to conventional office and ambulatory blood pressure (BP) components have been thoroughly investigated, ${ }^{6}$ their associations with circadian $\mathrm{BP}$ variation have not been studied to the same degree. ${ }^{7}$ In particular, only a limited number of studies have connected a blunted decrease in nighttime BP to arterial stiffness, ${ }^{8}$ increased urinary albumin excretion ${ }^{9}$ and increased levels of high sensitivity C-reactive protein (hs-CRP). ${ }^{10}$

Nevertheless, a blunted nighttime BP decrease (referred to as 'nondipping status') should be distinguished from 'nighttime hypertension
(NH)', in which the absolute nighttime BP values lie above the upper normal BP limits for the nighttime period. Importantly, $\mathrm{NH}$ may be present even in subjects with a dipping pattern of circadian BP variation, depending on their daytime BP levels. The implications of combined $\mathrm{NH}$ and a dipping-BP variation profile on arterial stiffening and microalbuminuria have never been investigated.

To eliminate any effects caused by the disturbance of circadian BP variability, we tested the hypothesis that, among dipper hypertensive subjects, those with $\mathrm{NH}$ would have a higher carotid-to-femoral pulse wave velocity (c-f PWV) and albumin-to-creatinine ratio (ACR) relative to patients with nighttime normotension (NN) and that nighttime $\mathrm{BP}$ is a more potent determinant of c- $\mathrm{f} \mathrm{PWV}$ and ACR than is daytime BP.

\section{METHODS}

Study population

This is a cross-sectional study involving 402 consecutive subjects with untreated stage I-II uncomplicated essential hypertension. Hypertension diagnosis and grading were based on recent guidelines ${ }^{11}$ for the management of arterial hypertension (office BP $\geqslant 140 / 90 \mathrm{~mm} \mathrm{Hg}$ ) and confirmed by 24 -h ambulatory 


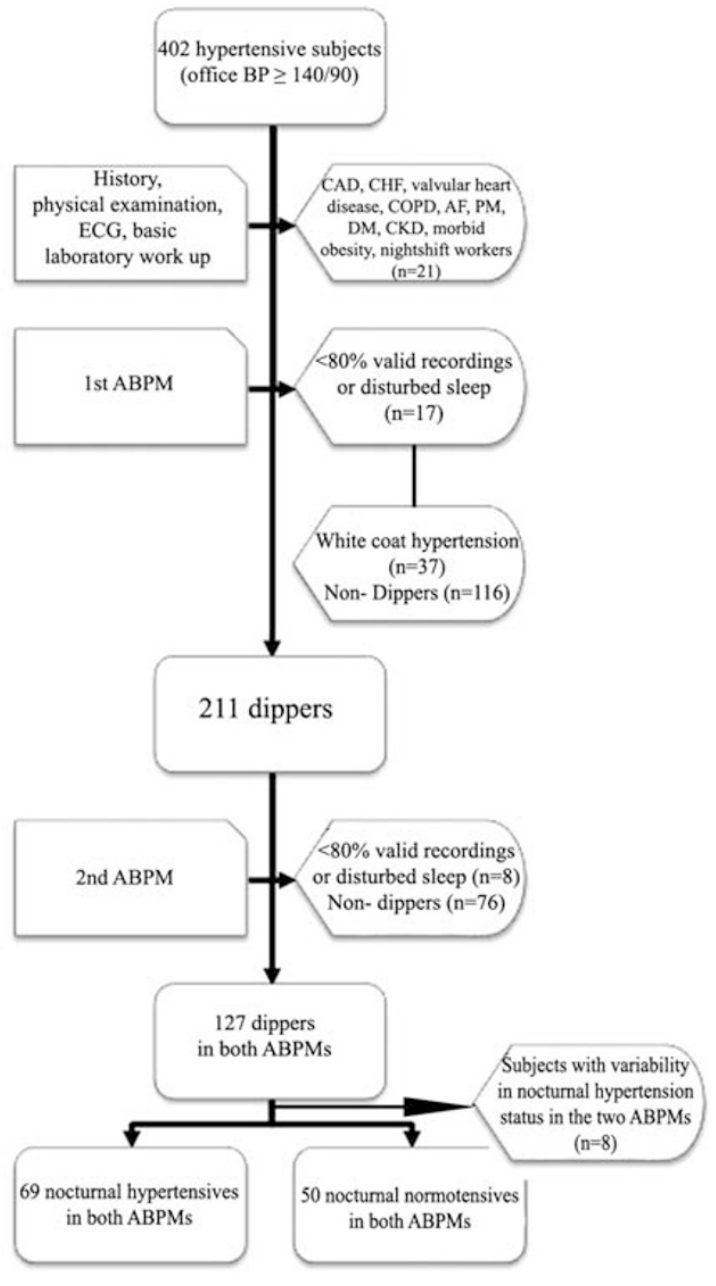

Echocardiography, hs- CRP, c.f PWV, ACR

Figure 1 Selection of the study population. The final study population consisted of 69 dipper nighttime hypertensive (NH) and 50 dipper nighttime normotensive (NN) subjects. Decrease in BP was calculated according to the equation: Decrease in $\mathrm{BP}=(($ daytime $\mathrm{BP}-$ nighttime $\mathrm{BP}) /$ daytime $\mathrm{BP}) \times 100$. ABPM, ambulatory BP monitoring; $A F$, atrial fibrillation; $B P$, blood pressure; $\mathrm{CAD}$, coronary artery disease; $\mathrm{CHF}$, congestive heart failure; $C K D$, chronic kidney disease; COPD, chronic obstructive pulmonary disease; DM, diabetes mellitus; PM, pacemaker.

BP $>130 / 80 \mathrm{~mm} \mathrm{Hg} .{ }^{11}$ The standard clinical and laboratory work-up was used to exclude subjects with secondary hypertension (Figure 1).

Subjects with a history or clinical signs of coronary heart disease, congestive heart failure, valvular heart disease, chronic obstructive pulmonary disease, permanent pacemaker or atrial fibrillation were excluded from the study, as were subjects with morbid obesity (body mass index $>40 \mathrm{~kg} / \mathrm{m}^{2}$ ), diabetes mellitus, chronic kidney disease or any other significant systemic disease. For a more accurate assessment of the circadian BP profile, subjects working in night shifts were excluded from the study.

The study protocol was approved by the ethics committee of our institution in accordance with the Declaration of Helsinki (1964) and the Declaration of Tokyo (1975; revised in 1983). All participants gave written informed consent.

\section{BP measurements: Definitions}

Office BP measurement was performed at three separate visits in our outpatient clinic, with a mean interval of one week, according to the Mostrecent guidelines. ${ }^{11}$ After having abstained from caffeine, exercise and smoking for at least $30 \mathrm{~min}$, patients remained seated for at least $5 \mathrm{~min}$ in a quiet environment; then, three BP measurements were taken at approximately 2 min intervals. The mean of the last two measurements provided each visit's $\mathrm{BP}$, and the average BP at the three visits represented office BP. Ambulatory BP was recorded over a working day (Monday through Friday) using automated Spacelabs 90207 units (Redmond, WA, USA). The procedure, which has been described in detail previously, ${ }^{7}$ was performed twice with a one-week interval. In brief, the cuff was fixed to the non-dominant arm and the device was set to automatically obtain $\mathrm{BP}$ and heart-rate readings at $15 \mathrm{~min}$ intervals during the day and $20 \mathrm{~min}$ intervals at night. Daytime and nighttime were defined as lasting from $10 \mathrm{am}$ to $8 \mathrm{pm}$ and from midnight to $6 \mathrm{am}$, respectively. The quality of sleep and daily physical activity were assessed through a questionnaire administered after the ambulatory BP was monitored.

Patients in our study population were classified as dippers (nighttime systolic and diastolic BP reduction $\geqslant 10 \%$ ) and non-dippers (nighttime systolic or diastolic BP reduction $<10 \%)$. The nighttime $\mathrm{BP}$ reduction was calculated using the following equation: $\mathrm{BP}$ reduction $=(($ daytime $\mathrm{BP}-$ nighttime $\mathrm{BP}) /$ daytime BP) $\times 100$. Subjects with a nighttime systolic BP $>120$ or a nighttime diastolic $\mathrm{BP}>70 \mathrm{~mm} \mathrm{Hg}$ were considered to be $\mathrm{NH}$ whereas subjects with corresponding values $\leqslant 120 / 70$ were considered to be $\mathrm{NN}$, irrespective of their $24 \mathrm{~h}$ and daytime BP values. Because of the poor reproducibility of variability in ambulatory BP, a second ambulatory recording was performed 1 week after the original recording to detect dippers and $\mathrm{NH}$ with maximal accuracy. This second recording revealed 127 invariably dipper subjects in both ambulatory BP monitoring sessions. These patients were subdivided into consistent (that is, in both ambulatory BP monitoring sessions), $\mathrm{NH}(n=69)$ and $\mathrm{NN}(n=50)$, who constituted the final study population (Figure 1). Subjects with less than $80 \%$ valid awake or asleep recordings in each ambulatory BP assessment $(n=14)$ were excluded from the study, as were those who reported significant procedure-related sleep disruption $(n=11)$.

All participants underwent a thorough clinical examination and a metabolic profile evaluation including a measurement of high hs-CRP, 12-lead ECG, a complete echocardiographic examination, as well as c-f PWV and ACR measurement.

\section{Arterial stiffness assessment}

All patients were studied between 9:00 am and 11:00 am in the supine position after a minimum of $10 \mathrm{~min}$ of rest at a comfortable room temperature. A trained clinician, blinded to the subjects' ambulatory BP monitoring data, measured c-f PWV using a validated noninvasive automatic device (Complior SP equipment and software, Artech-Medical, Paris, France), as previously described. ${ }^{12}$ Five consecutive readings were obtained for each subject; the mean of these readings is reported as the patient's c-f PWV.

\section{Laboratory determinations}

ACR was determined by a quantitative assay (DCA 2000, Bayer Diagnostics, Europe, Dublin, Ireland) with a coefficient of variation of $2.8 \%$. Two measurements of two nonconsecutive spot urine samples were performed and the average is presented as the subject's ACR.

Venous blood sampling was performed between 8:00 am and 9:00 am following overnight fasting to evaluate glycemia, lipid profile, serum uric acid, creatinine and electrolyte levels, and hs-CRP. The estimated glomerular filtration rate was estimated according to the following formula, which was developed and validated in a population of predominantly white adult subjects with normal renal function: glomerular filtration rate $\left(\mathrm{ml} \mathrm{min}^{-1}\right.$ per $\left.1.73 \mathrm{~m}^{2}\right)$ $=224 \times$ serum creatine $\left(\mathrm{mg} \mathrm{dl}^{-1}\right)^{-0.490} \times$ age $(\text { years })^{-0.192} \times 0.923$ (if female).$^{13}$ Levels of hs-CRP were assessed using a validated high-sensitivity assay (Dade Behring CardioPhase hsCRP Assay, Marburg, Germany) with a coefficient of variation of $3.4 \%$

\section{Echocardiography}

All participants underwent echocardiographic examination by an experienced senior echocardiographer who was blinded to the subjects' BP and clinical data. The examination was performed using a General Electric Medical System Vivid 3 PRO ultrasound imager (General Electric, Milwaukee, WI, USA) equipped 
with a $2.5-5 \mathrm{MHz}$ transducer according to the guidelines of the American Society of Echocardiography. ${ }^{14}$ Left atrial diameter was measured by $2 \mathrm{D}$-guided M-mode echocardiography obtained in the parasternal short-axis view at the base of the heart and was indexed for body surface area to provide the left atrial diameter index. ${ }^{15}$ The left ventricular mass was computed by the formula introduced by Devereux et al. ${ }^{14}$ and was indexed by height ${ }^{2.7}$, because of an average body mass index that was above normal limits in this patient population, to provide the left ventricular mass index. The relative wall thickness was estimated as the sum of the interventricular septum and posterior wall thickness divided by the end diastolic left ventricular diameter. The mitral annulus $\mathrm{E}$ and $\mathrm{A}$ wave peak velocities and their ratio in tissue Doppler imaging along with the standard Doppler indices of the left ventricular diastolic filling (transmitral flow peak $\mathrm{E}$ and $\mathrm{A}$ wave velocities, $\mathrm{E} / \mathrm{A}$ ratio, isovolumic relaxation time, E wave deceleration time), were assessed as indices of diastolic function. ${ }^{14}$

\section{Statistical analysis}

Continuous data were described as the means \pm s.d., if normally distributed, or as medians with interquartile range if asymmetrically distributed. On account of a skewed distribution, c-f PWV, ACR and hs-CRP values were $\log _{10}$ transformed, and normality was confirmed before statistical analyses. Categorical data are presented as absolute and relative frequencies. Comparisons between groups were performed by Student's $t$-test or $\chi^{2}$ test as appropriate. Analysis of covariance was used to test for differences between groups after adjustment for confounders. The bivariate associations of $\log _{10}(\mathrm{c}-\mathrm{f} \mathrm{PWV})$ and $\log _{10}$ (ACR) with office BP and $24 \mathrm{~h}$ BP were each assessed with a simple Pearson's coefficient of correlation. We tested for significant differences among the Pearson correlation coefficients with Steiger's $z$-test for correlated correlations within one population.

Independent correlates of increased central arterial stiffness and urine albumin excretion were assessed by standard multiple linear regression analyses with continuous $\log _{10}\left(\mathrm{c}-\mathrm{f}\right.$ PWV) and $\log _{10}(\mathrm{ACR})$ as the dependent variable. We implemented a separate regression model for each of the BP components of interest ( $24 \mathrm{~h}$, daytime and nighttime BP) that was used as an explanatory variable, and we compared the resulting adjusted $R^{2}$ of the three (per dependent variable) models and the standardized $\beta$ 's of the three BP components. The other candidate-independent explanatory variables for $\log _{10}$ (c-f PWV) included age, male gender, waist circumference, $24 \mathrm{~h}$ heart rate, $\log _{10}$ (hs-CRP) and nighttime decrease in systolic BP. The candidate explanatory variables for $\log _{10}$ (ACR) included, in addition to the relevant BP component, male gender, waist circumference, $\log _{10}$ (hs-CRP), high density lipoprotein and nighttime decrease in systolic BP. The variables entered into the regression models as covariates were selected on the basis of their bivariate associations, or established pathophysiological relationships with c-f PWV and ACR. Colinearity diagnostics were run in all built regression models and a tolerance cutoff value of $\geqslant 0.1$ and a corresponding variance inflation factor below 10 was used to rule out multicollinearity. All statistical analyses were performed with SPSS version 15.0 (SPSS, Chicago, IL, USA). A two-tailed $P$-value of 0.05 or lower was regarded as significant.

\section{RESULTS}

Comparison of hemodynamic load, arterial stiffness and urinary albumin excretion in $\mathrm{NH}$ and $\mathrm{NN}$ dippers

Clinical and laboratory data are provided in Table 1.

$\mathrm{NH}$ compared with NN dippers had, by definition, higher $24 \mathrm{~h}$ systolic, diastolic and pulse pressure $(143 \pm 9$ vs. $131 \pm 5,89 \pm 6$ vs. $85 \pm 9$ and $54 \pm 7$ vs. $46 \pm 12 \mathrm{~mm} \mathrm{Hg}$, respectively; $P<0.001$ for all cases) and higher systolic and diastolic daytime BP values (147 $\pm 9 v s$. $136 \pm 8$ and $92 \pm 10$ vs. $82 \pm 9 \mathrm{~mm} \mathrm{Hg}$, respectively; $P<0.001$ for both cases). They also had a lower nighttime decrease in systolic BP $(13 \pm 3$ vs. $16 \pm 4 \%, P<0.0001$ ), whereas differences in the nighttime decrease in diastolic BP were of borderline significance, with lower values in the $\mathrm{NH}$ group ( $14 \pm 2$ vs. $15 \pm 2 \%, P=0.056$ ) (Table 2 ).

$\mathrm{NH}$ dippers had significantly higher $\log _{10}$ (c-f PWV) $(0.92 \pm 0.07$ vs. $0.87 \pm 0.05, P<0.0001)$ and higher $\log _{10}(\mathrm{ACR})$ values $(1.20 \pm 0.50 \mathrm{vs}$. $1.02 \pm 0.27, P=0.01$ ) (Table 3).
Table 1 Demographic, clinical and laboratory data of the study population

\begin{tabular}{|c|c|c|c|}
\hline & $\begin{array}{c}\text { Dipper NH } \\
(\mathrm{n}=69)\end{array}$ & $\begin{array}{c}\text { Dipper NN } \\
(\mathrm{n}=50)\end{array}$ & $\mathrm{P}$ \\
\hline Age (years) & $48 \pm 6$ & $49 \pm 4$ & 0.58 \\
\hline Gender (\% male) & 66.6 & 67.3 & 0.37 \\
\hline $\mathrm{BMI}\left(\mathrm{Kg} \mathrm{m}^{-2}\right)$ & $29.0 \pm 3.4$ & $28.6 \pm 4$ & 0.23 \\
\hline Waist circumference $(\mathrm{cm})$ & $104.8 \pm 5.1$ & $98 \pm 4.6$ & $<0.01$ \\
\hline Hypertension duration (years) & $1.0 \pm 0.6$ & $0.93 \pm 0.8$ & 0.11 \\
\hline Smoking (\%) & 38.4 & 45.9 & 0.32 \\
\hline Serum uric acid $\left(\mathrm{mg} \mathrm{dl}^{-1}\right)$ & $5.9 \pm 1.6$ & $5.0 \pm 1.3$ & $<0.01$ \\
\hline Serum glucose $\left(\mathrm{mg} \mathrm{dl}^{-1}\right)$ & $97.9 \pm 8$ & $96.1 \pm 8$ & 0.48 \\
\hline Total cholesterol ( $\left.\mathrm{mg} \mathrm{dl}^{-1}\right)$ & $224 \pm 28$ & $223 \pm 30$ & 0.89 \\
\hline Triglycerides $\left(\mathrm{mg} \mathrm{dl}^{-1}\right)$ & $164 \pm 45$ & $156 \pm 43$ & 0.01 \\
\hline High density lipoprotein $\left(\mathrm{mg} \mathrm{dl}^{-1}\right.$ ) & $46 \pm 9$ & $52 \pm 10$ & 0.03 \\
\hline Low density lipoprotein $\left(\mathrm{mgdl}^{-1}\right)$ & $145 \pm 31$ & $141 \pm 3$ & 0.8 \\
\hline
\end{tabular}

Abbreviations: BMI, body mass index; $\mathrm{NH}$, nighttime hypertensive; NN, nighttime normotensive. All continuous variables are presented as mean \pm s.d. whereas categorical variables are presented as relative frequencies.

Table 2 Blood pressure data

\begin{tabular}{|c|c|c|c|}
\hline & $\begin{array}{c}\text { Dipper NH } \\
(\mathrm{n}=69)\end{array}$ & $\begin{array}{c}\text { Dipper } \\
\text { NN (50) }\end{array}$ & $\mathrm{P}$ \\
\hline Office systolic BP (mm Hg) & $150 \pm 12$ & $149 \pm 11$ & 0.35 \\
\hline Office diastolic BP (mm Hg) & $100 \pm 7$ & $96 \pm 9$ & 0.01 \\
\hline Office pulse pressure (mm Hg) & $50 \pm 12$ & $52 \pm 13$ & 0.68 \\
\hline Office heart rate (bpm) & $81 \pm 10$ & $78 \pm 8$ & 0.66 \\
\hline $24 \mathrm{~h}$ systolic BP $(\mathrm{mm} \mathrm{Hg})$ & $143 \pm 9$ & $131 \pm 5$ & $<0.001$ \\
\hline $24 \mathrm{~h}$ diastolic BP $(\mathrm{mm} \mathrm{Hg})$ & $89 \pm 6$ & $85 \pm 9$ & $<0.001$ \\
\hline $24 \mathrm{~h}$ pulse pressure $(\mathrm{mm} \mathrm{Hg})$ & $54 \pm 7$ & $46 \pm 12$ & $<0.001$ \\
\hline $24 \mathrm{~h}$ heart rate (bpm) & $76 \pm 9$ & $80 \pm 10$ & 0.03 \\
\hline Daytime systolic BP (mm Hg) & $147 \pm 9$ & $136 \pm 8$ & $<0.001$ \\
\hline Daytime diastolic BP ( $\mathrm{mm} \mathrm{Hg})$ & $92 \pm 10$ & $82 \pm 9$ & $<0.001$ \\
\hline Daytime pulse pressure (mm Hg) & $55 \pm 8$ & $54 \pm 11$ & 0.78 \\
\hline Daytime heart rate (bpm) & $80 \pm 9$ & $80 \pm 9$ & 0.66 \\
\hline Nighttime systolic BP (mm Hg) & $132 \pm 7$ & $111 \pm 3$ & $<0.001$ \\
\hline Nighttime diastolic BP (mm Hg) & $82 \pm 6$ & $62 \pm 2$ & $<0.001$ \\
\hline Nighttime pulse pressure ( $\mathrm{mm} \mathrm{Hg}$ ) & $50 \pm 8$ & $49 \pm 4$ & 0.63 \\
\hline Nighttime heart rate (bpm) & $68 \pm 8$ & $66 \pm 6$ & 0.37 \\
\hline Systolic BP fall (\%) & $13 \pm 3$ & $16 \pm 4$ & $<0.001$ \\
\hline Diastolic BP fall (\%) & $14 \pm 2$ & $15 \pm 2$ & 0.056 \\
\hline
\end{tabular}

Abbreviations: BP, blood pressure; bpm, beats per minute; NH, nighttime hypertensives; NN, nighttime normotensives.

Variables are presented as mean \pm s.d.

Analysis of covariance revealed that, after adjusting for $24 \mathrm{~h}$ systolic BP levels, the differences in $\log 10$ (c-f PWV) between NH and NN dippers $(F=7.87, P<0.01$, partial eta squared $=0.062)$ and $\log _{10}(\mathrm{ACR})$ ( $F=6.99, P<0.01$, partial eta squared $=0.056)$ remained significant. However, as expected, there was a strong relationship between $24 \mathrm{~h}$ systolic $\mathrm{BP}$ and $\log _{10}(\mathrm{c}-\mathrm{f} \mathrm{PWV})(F=30.26, P<0.001$, partial eta squared $=$ $0.203)$ and $\log _{10}(\mathrm{ACR})(F=36.6, P<0.001$, partial eta squared $=0.237)$.

$\mathrm{NH}$ and NN patients exhibited similar values for left atrial diameter index, left ventricular mass index and relative wall thickness. However, $\mathrm{NH}$ patients exhibited a lower rate of transmitral $\mathrm{E}$ to A wave peak velocities, higher isovolumic relaxation times and a lower mitral annulus tissue Doppler imaging Ea to Aa ratio (Table 3). 
Table 3 Target-organ damage indexes according to nighttime BP classification

\begin{tabular}{|c|c|c|c|}
\hline & $N H(\mathrm{n}=69)$ & $N N(\mathrm{n}=50)$ & $\mathrm{P}$ \\
\hline \multicolumn{4}{|l|}{ Blood vessels } \\
\hline$c-f$ PWVa & $8.3(1.9)$ & $7.55(1.4)$ & - \\
\hline $\log _{10}(c-f P W V)$ & $0.92 \pm 0.07$ & $0.87 \pm 0.05$ & $<0.001$ \\
\hline \multicolumn{4}{|l|}{ Kidney } \\
\hline ACR $\left(\mathrm{mgg}^{-1}\right)^{\mathrm{a}}$ & $15.7(12.7)$ & $11(9.8)$ & - \\
\hline $\log _{10}(A C R)$ & $1.20 \pm 0.50$ & $1.02 \pm 0.27$ & 0.01 \\
\hline Serum creatinine $\left(\mathrm{mg} \mathrm{dl}^{-1}\right)$ & $0.96 \pm 0.15$ & $0.91 \pm 0.16$ & 0.1 \\
\hline e-GFR ( $\left.\mathrm{ml} \mathrm{min}-11.73 \mathrm{~m}^{-2}\right)$ & $108.2 \pm 8.0$ & $109.1 \pm 7.7$ & 0.68 \\
\hline \multicolumn{4}{|l|}{ Heart } \\
\hline Left ventricular mass index $\mathrm{g} \mathrm{m}^{-2.7}$ & $92.6 \pm 22.6$ & $89.0 \pm 20.7$ & 0.38 \\
\hline Relative wall thickness & $0.46 \pm 0.1$ & $0.48 \pm 0.09$ & 0.33 \\
\hline $\begin{array}{l}\text { Transmitral } \mathrm{E} \text { to } \mathrm{A} \text { wave peak } \\
\text { velocities ratio }\end{array}$ & $0.93 \pm 0.2$ & $1.03 \pm 0.1$ & 0.03 \\
\hline Isovolumic relaxation time & $101.8 \pm 20.6$ & $93.0 \pm 16.3$ & 0.01 \\
\hline $\begin{array}{l}\text { Mitral annulus TDI Ea to Aa wave } \\
\text { peak velocities ratio }\end{array}$ & $0.71 \pm 0.2$ & $1.03 \pm 0.87$ & 0.01 \\
\hline Left atrial diameter index $\mathrm{cm} \mathrm{m}^{-2}$ & $1.88 \pm 0.27$ & $1.94 \pm 0.22$ & 0.18 \\
\hline
\end{tabular}

Abbreviations: ACR, albumin to creatinine reation; c-f PWV, carotid to femoral pulse wave velocity; e-GFR, estimated glomerular filtration rate computed with formula: GFR,

$\left(\mathrm{mlmin}^{-1} 1.73 \mathrm{~m}^{-2}\right)=224 \times$ serum creatine $\left(\mathrm{mgdl}^{-1}\right)^{-0.490} \times$ age $(\text { years })^{-0.192} \times 0.923$

(if female); $\mathrm{NH}$, nighttime hypertensive dippers; NN, nighttime normotensive dippers;

TDI, tissue Doppler imaging.

aData with assymetrical distribution presented as median (interquartile range)

\section{Independent correlates of aortic stiffness and urinary albumin} excretion

We estimated and compared the simple linear associations of $\log _{10}(\mathrm{c}-\mathrm{f}$ $\mathrm{PWV}$ ) and $\log _{10}$ (ACR) with the various office and $24 \mathrm{~h}$ BP components. $\log _{10}(\mathrm{c}-\mathrm{f} \mathrm{PWV})$ correlated more strongly with nighttime systolic BP $(r=0.37, P<0.0001)$ than with daytime systolic BP $(r=0.24$, $P=0.007)$ ( $P$ of the comparison of $r$-values $<0.05$ ). In the same way, $\log _{10}($ ACR $)$ exhibited a stronger correlation with nighttime systolic BP $(r=0.52, P<0.0001)$ than with daytime systolic BP ( $r=0.38, P<0.0001$ ) ( $P$ of the comparison of $r$-values $<0.05)$.

We evaluated the independent determinants of c-f PWV in three models, implementing in each one of the following ambulatory BP components: $24 \mathrm{~h}$ (model A), daytime (model B) and nighttime systolic BP (model C). In contrast with nighttime systolic BP (model C), daytime systolic BP was not a significant determinant of c-f PWV in model B. The adjusted $R^{2}$ values were $0.34,0.33$ and 0.37 for models A, B and C, respectively. This is compatible with a greater effect size of nighttime BP (model C) in the prediction of PWV. The standardized in the regression models denote that for every s.d. of increase in nighttime or $24 \mathrm{~h}$ systolic BP, c-f PWV would increase by 0.280 and 0.213 s.d., respectively, which is also compatible with a higher prognostic significance of nighttime systolic BP over $24 \mathrm{~h}$ systolic BP. The other independent determinants of c-f PWV were age and serum uric-acid levels (Table 4).

Similarly, the independent correlates of ACR were assessed in three different models using a different component of ambulatory BP in each: $24 \mathrm{~h}$, daytime and nighttime systolic BP (models a, b and c, respectively). The corresponding adjusted $R^{2}$ values were $0.53,0.51$ and 0.51, respectively. Daytime systolic BP was not a significant determinant of ACR in model (b). In contrast, nighttime systolic BP was a significant determinant of ACR, although less powerful than $24 \mathrm{~h}$ systolic BP. The other independent determinants of ACR in each
Table 4 Independent determinants of PWV in three multiple regression analysis models implementing in each $24 \mathrm{~h}$ systolic BP or daytime systolic BP or nighttime systolic BP

$\log _{10}(c-f P W V)$

\begin{tabular}{|c|c|c|c|c|}
\hline $\begin{array}{l}\text { Explanatory variables } \\
\text { entering the } \\
\text { multivariable models }\end{array}$ & $\begin{array}{c}\text { Standardizec } \\
\beta\end{array}$ & $\begin{array}{c}\text { Unstandardized } \\
\beta\end{array}$ & $\begin{array}{c}95 \% \mathrm{Cl} \\
\text { for } \beta\end{array}$ & P-value \\
\hline \multicolumn{5}{|c|}{ Model $A$ with $24 h$ systolic $B P$ as a covariate (Adjusted $\mathrm{R}^{2}=0.34, \mathrm{P}<0.001$ ) } \\
\hline Age & 0.427 & 0.004 & $0.003-0.006$ & $<0.001$ \\
\hline Male gender & 0.073 & 0.014 & $-0.028-0.055$ & 0.51 \\
\hline Waist circumference & 0.096 & 0.001 & $0.000-0.002$ & 0.37 \\
\hline $24 \mathrm{~h}$ heart rate & 0.158 & 0.001 & $0.000-0.002$ & 0.07 \\
\hline $\log _{10}($ hs-CRP) & 0.071 & 0.014 & $-0.029-0.058$ & 0.51 \\
\hline Uric acid & 0.229 & 0.011 & $0.001-0.021$ & 0.02 \\
\hline $24 \mathrm{~h}$ systolic BP & 0.213 & 0.002 & $0.000-0.003$ & 0.03 \\
\hline \multicolumn{5}{|c|}{ Model $B$ with daytime systolic BP as a covariate (Adjusted $\mathrm{R}^{2}=0.33, \mathrm{P}<0.001$ ) } \\
\hline Age & 0.439 & 0.004 & $0.003-0.006$ & $<0.001$ \\
\hline Male gender & 0.088 & 0.016 & $-0.025-0.058$ & 0.43 \\
\hline Waist circumference & 0.09 & 0.001 & $0.000-0.002$ & 0.4 \\
\hline $24 \mathrm{~h}$ heart rate & 0.155 & 0.001 & $0.000-0.002$ & 0.08 \\
\hline $\log _{10}$ (hs-CRP) & 0.096 & 0.019 & $-0.024-0.062$ & 0.37 \\
\hline Uric acid & 0.243 & 0.012 & $0.002-0.021$ & 0.01 \\
\hline Daytime systolic BP & 0.176 & 0.001 & $0.000-0.003$ & 0.06 \\
\hline \multicolumn{5}{|c|}{ Model $C$ with nighttime $B P$ as a covariate (Adjusted $\mathrm{R}^{2}=0.37, \mathrm{P}<0.001$ ) } \\
\hline Age & 0.413 & 0.004 & $0.002-0.006$ & $<0.001$ \\
\hline Male gender & 0.044 & 0.008 & $-0.033-0.050$ & 0.69 \\
\hline Waist circumference & 0.102 & 0.001 & $0.000-0.002$ & 0.33 \\
\hline $24 \mathrm{~h}$ heart rate & 0.17 & 0.001 & $0.000-0.003$ & 0.05 \\
\hline $\log _{10}($ hs-CRP) & 0.042 & 0.008 & $-0.034-0.050$ & 0.69 \\
\hline Uric acid & 0.243 & 0.12 & $0.002-0.021$ & 0.01 \\
\hline Nighttime systolic BP & 0.280 & 0.002 & $0.001-0.003$ & $<0.01$ \\
\hline
\end{tabular}

Abbreviations: BP, blood pressure; c-f PWV, carotid to femoral pulse wave velocity; hs-CRP, high sensitivity $C$ reactive protein. -f PWV or on the basis of known pathophysiologic relationships with arterial stiffness. Bold characters are used to highlight $P$ values indicating statistical significance or significant differences in standardized Betas among the BP components of interest.

model included waist circumference, $\log _{10}$ (hs-CRP) and nighttime decrease in systolic BP (Table 5).

\section{DISCUSSION}

The main finding of our study is that nighttime compared with daytime systolic BP is a more specific determinant of arterial stiffness and urinary albumin excretion in untreated stage I-II dipper NH. Accordingly, NH dippers had significantly increased c-f PWV and ACR compared with NN. Moreover, inflammatory activation (as reflected by hs-CRP levels) is also more intense in dipper $\mathrm{NH}$ than in their NN counterparts.

This is the first study to detect and examine the effects of $\mathrm{NH}$ on target-organ damage (TOD) in subjects with a day to night BP reduction of $\geqslant 10 \%$. It is plausible that the definition of dipping as a $10 \%$ relative nighttime $\mathrm{BP}$ reduction allows subjects with nighttime $\mathrm{BP}$ well above the limits of $\mathrm{NH}$ to be registered as dippers in relative studies. Our study supports the notion that dipping and $\mathrm{NH}$ can coincide in the same subjects and that nighttime BP has a significant role in the pathophysiological sequence in this setting.

Our findings are in accordance with previous studies that have linked c-f PWV, ACR and hs-CRP ${ }^{9,16,17}$ to nighttime BP in hypertension 
Table 5 Independent determinants of ACR in three multiple regression analysis models implementing in each $24 \mathrm{~h}$ systolic BP or daytime systolic BP or nighttime systolic BP

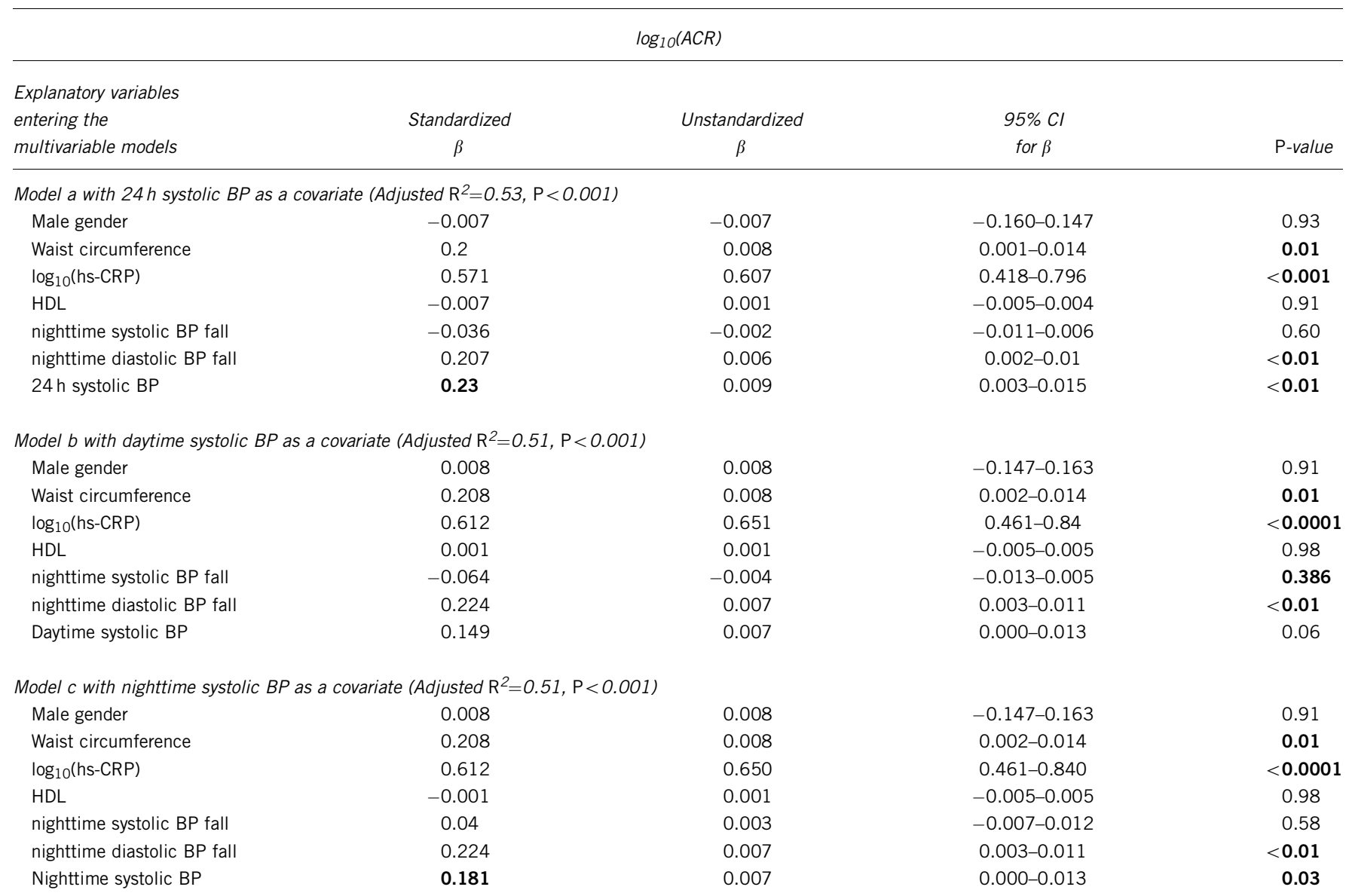

Abbreviations: ACR, albumin to creatinine ratio; BP, blood pressure; hs- CRP, high sensitivity C reactive protein; HDL, high density lipoprotein.

Variables entering the models were those with significant bivariate correlations with ACR or on the basis of known pathophysiologic relationships with arterial stiffness and microalbuminuria. Bold characters are used to highlight $P$ values indicating statistical significance or significant differences in standardized Betas among the BP components of interest.

and suggested that nighttime BP has a closer relationship with TOD development and a higher prognostic role regarding cardiovascular outcome than does $24 \mathrm{~h} \mathrm{BP}{ }^{18}$ In our population, nighttime systolic BP exhibited a closer relationship with c-f PWV than did daytime or $24 \mathrm{~h}$ systolic BP. Similarly, nighttime BP was more strongly associated with ACR than was daytime BP. These relationships were observed in both bivariate correlations and the constructed multiple-linear regression models. In the absence of any physical and mental stressors during sleep, nighttime BP may coincide with the minimal BP that is required for sufficient perfusion of the peripheral organs and tissues during the night. ${ }^{18}$ Maintenance of nighttime BP above these basal limits might disproportionally increase the hemodynamic load imposed upon the cardiovascular system and consequently trigger or accelerate the development of TOD; this effect could explain the above-mentioned associations. In addition, the absence of any physical and mental activity during the night may reduce the BP variability that can be represented only partially in a non-continuous $\mathrm{BP}$ recording. Thus, nighttime $\mathrm{BP}$ is a more consistent and reproducible expression of hypertensionassociated hemodynamic load.

The interrelationship between hemodynamic load, arterial stiffness and urinary albumin excretion has been reported previously, and may occur because of microvascular kidney damage induced by high pulsatile stress ${ }^{19}$ and/or by a diffuse endothelial dysfunction and low grade vascular inflammation that promote both stiffness and albuminuria. ${ }^{3}$ The latter etiology is in-line with our finding of hs-CRP as an independent correlate of ACR and suggests a potential pathogenetic interplay between stiffness, inflammation and renal damage. Moreover, our study cohort consists of subjects in the early stages of hypertension who have had the disease for only a short duration. It is possible that this limited length of exposure to hypertrophic stimuli is not sufficient to cause differences in left ventricular mass between our $\mathrm{NH}$ and NN subgroups. However, NH compared with NN dippers exhibited more affected indices of left ventricular diastolic function, indicating an early cardiac adaptation that usually precedes the development of left ventricular hypertrophy in hypertensive subjects.

From a clinical standpoint, our findings suggest that nighttime BP assessment may be useful in the risk stratification and management of hypertension. Moreover, non-dipping status and NH BP are not identical entities, and NH may coexist with both dipping and nondipping patterns of BP variation. Thus, it would be most appropriate to evaluate both absolute nighttime BP values and dipping status to maximize the prognostic information that is derived from the study of nighttime BP. In addition, aiming to lower nighttime BP values as part of the therapeutic strategy may lead to the implementation of techniques such as chronotherapy, which takes advantage of the differences in the kinetics and the effects of hypertension medications taken at different times of the day. 
The limited size of our rather selective hypertensive cohort, their relatively short durations of essential hypertension and the impressively high proportion of dipper $\mathrm{NH}$ limit the generalizability of our results. Furthermore, the cross-sectional nature of our study limits our ability to link $\mathrm{NH}$ with outcome in this population. However, the repetition of ambulatory $\mathrm{BP}$ monitoring and the strict criteria for the definition of dipping status and $\mathrm{NH}$ strengthen the reliability of our results.

In conclusion, nighttime BP is associated more closely with c-f PWV and ACR in dipper hypertensive patients than is daytime BP. These findings imply that, even in patients with a dipper profile, absolute nighttime BP values should be taken into account for the prediction of surrogate end points such as arterial stiffness and urinary albumin excretion.

\section{CONFLICT OF INTEREST}

The authors declare no conflict of interest.

1 Laurent S, Cockcroft J, Van Bortel L, Boutouyrie P, Giannattasio C, Hayoz D, Pannier B, Vlachopoulos C, Wilkinson I, Struijker-Boudier H. Expert consensus document on arterial stiffness: methodological issues and clinical applications. Eur Heart J 2006; 27: 2588-2605.

2 Laurent S, Boutouyrie P, Asmar R, Gautier I, Laloux B, Guize L, Ducimetiere P, Benetos A. Aortic stiffness is an independent predictor of all- cause and cardiovascular mortality in hypertensive patients. Hypertension 2001; 37: 1236-1241.

3 Van den Meiracker AH, Mattace-Raso FUS. Large artery stiffness and microalbuminuria. A causal relationship? J Hypertens 2009; 27: 1355-1357.

4 Tsioufis C, Dimitriadis K, Taxiarchou E, Vasiliadou C, Chartzoulakis G, Tousoulis D, Manolis A, Stefanadis C, Kallikazaros I. Diverse associations of microalbuminuria with C- reactive protein, interleukin-18 and soluble CD 40 ligand in male essential hypertensive subjects. Am J Hypertens 2006; 19: 462-466.

5 Hillege HL, Fidler V, Diercks GF, van Gilst WH, de Zeeuw D, van Veldhuisen DJ, Gans RO, Janssen WM, Grobbee DE, de Jong PE. Prevention of renal, vascular end stage disease (PREVEND) study group. urinary albumin excretion predicts cardiovascular and noncardiovascular mortality in general population. Circulation 2002; 106: 1777-1782.

6 Willum-Hansen T, Staessen JA, Torp-Pedersen C, Rasmussen S, Thijs LIbsen H, Jeppesen J. Prognostic value of aortic pulse wave velocity as index of arterial stiffness in the general population. Circulation 2006; 113: 664-670.
7 Tsioufis C, Tzioumis K, Dimitriadis K, Chatzis D, Skiadas I, Michailidis A, Toutouzas P, Kallikazaros I, Stefanadis C. Nondipping status does not attenuate the conjugated estrogen-induced improvement in aortic stiffness in postmenopausal women with untreated hypertension. Am J Hypertens 2005; 18: 607-611.

8 Lekakis JP, Zakopoulos NA, Protogerou AD, Papaioannou TG, Kotsis VT, Pitiriga VCh, Tsitsirikos MD, Stamatelopoulos KS, Papamichael CM, Mavrikakis ME. Arterial stiffness assessed by pulse wave analysis in essential hypertension: relation to 24-h blood pressure profile. Int J Cardiol 2005; 102: 391-395.

9 Redon J, Liao Y, Lozano JV, Miralles A, Pascual JM, Cooper RS. Ambulatory blood pressure and microalbuminuria in essential hypertension: role of circadian variability. J Hypertens 1994; 12: 947-953.

10 Tsioufis C, Syrseloudis D, Dimitriadis K, Thomopoulos C, Tsiachris D, Pavlidis P, Selima M, Kallikazaros I, Stefanadis C. Disturbed circadian blood pressure rhythm and C-reactive protein in essential hypertension. J Hum Hypertens 2008; 22: 501-508.

11 Mancia G, De Backer G, Dominiczak A, Cifkova R, Fagard R, Germano G, Grassi G, Heagerty AM, Kjeldsen SE, Laurent S, Narkiewicz C, Ruilope L, Rynkiewicz A, Schmieder RE, Struijker Boudier HJA, Zanchetti A. 2007 Guidelines for the management of arterial hypertension. Eur Heart J 2007; 28: 1462-1536.

12 Tsioufis C, Dimitriadis K, Selima M, Thomopoulos C, Mihas C, Skiadas I, Tousoulis D, Stefanadis C, Kallikazaros I. Low-grade inflammation and hypoadiponectinaemia have an additive detrimental effect on aortic stiffness in essential hypertensive patients. Eur Heart J 2007; 28: 1162-1169.

13 Rule AD, Larson TS, Bergstralh EJ, Slezak JM, Jacobsen SJ, Cosio FG. serum creatinine to estimate glomerular filtration rate: accuracy in good health and in chronic kidney disease. Ann Intern Med 2004; 141: 929-937.

14 Gottdiener JS, Bednarz J, Devereux R, Gardin J, Klein A, Manning WJ, Morehead A, Kitzman D, Oh J, Quinones M, Schiller NB, Stein JH, Weissman NJ. American society of echocardiography: recommendations for use of echocardiography in clinical trials; a report from the american society of echocardiography. J Am Soc Echocardiogr 2004; 17: $1086-1119$

15 Tsioufis C, Taxiarchou E, Syrseloudis D, Chatzis D, Tsiachris D, Chatzistamatiou E, Skiadas I, Metallinos G, Tsiamis E, Stefanadis C. Left ventricular mass but not geometry determines left atrial size in the early stages of hypertension. J Hum Hypertens 2009; 23: 668-673.

16 Li Y, Staessen JA, Lu L, Li LH, Wang GL, Wang JG. Is isolated nocturnal hypertension a novel clinical entity?: Findings from a Chinese population study. Hypertension 2007; 50: 333-339.

17 Mitchell TH, Nolan B, Henry M, Cronin C, Baker H, Greely G. Microalbuminuria in patients with non-insulin-dependent diabetes mellitus relates to nocturnal systolic blood pressure. Am J Med 1997; 102: 531-535.

18 Fagard RH, Celis H, Thijs L, Staessen JA, Clement DL, De Buyzere ML, De Bacquer DA. Daytime and night-time blood pressure as predictors of death and cause-specific cardiovascular events in hypertension. Hypertension 2008; 51: 55-61.

19 O'Rourke MF, Safar ME. Relationship between aortic stiffening and microvascular disease in brain and kidney. Cause and logic of therapy. Hypertension 2005; 46 : 200-204. 